Savunma Bilimleri Dergisi

The Journal of Defense Sciences

Kasim / Nov 2019, Cilt/Volume 18/2, Say1/Issue 36.

ISSN (Bas111) : 1303-6831 ISSN (Online): 2148-1776

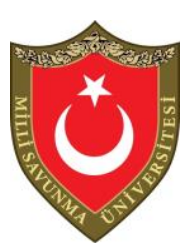

\title{
Rol Belirsizliğinin İş Tatmini ve İşten Ayrılma Üzerindeki Etkisi*
}

\author{
Ali GÜRSOY $^{* *}$, Kemal KÖKSAL ${ }^{* * *}$ ve Hakan YAPAR ${ }^{* * * *}$ \\ $\ddot{O}_{z}$
}

Rol belirsizliğinin, çalışanların stresini artırarak olumsuz iş tutum ve davranıslarına neden olduğu ifade edilmektedir. Ulusal ve uluslararası alanda rol belirsizliğinin özellikle iş tatmini üzerindeki etkisine yönelik yapılan çalışmalar incelendiğinde, her zaman olumsuz anlaml etkinin olmadĭ̆g görülmektedir. Bu çalışmanın amacı, rol belirsizliğinin iş tatmini üzerindeki farklı sonuçlarından hareketle, ortak yöntem varyans (OYV) problemi kontrol altına alınarak, rol belirsizliği ile iş tatmini iliş̧kisinin test edilmesidir. Bu maksatla, değişkenlere ait veriler zamansal bölümleme ve özel kodlama yapılarak, birer haftalık arayla, kamuda çalışan 227 katılımcıdan toplamda üç haftada toplanmıştır. OYV probleminin kontrol edilmesinden sonra korelasyon ve regresyon analizleri yapılarak araştırmanın hipotezleri test edilmiştir. Büyük ölçekli bir kamu kurumunda gerçekleştirilen araştırma sonucunda, rol belirsizliğinin iş tatmini üzerinde anlaml pozitif etkisi ve işten ayrlma niyeti üzerinde ise anlaml negatif etkisi olduğu tespit edilmiştir. Araştırma bulgularının sosyal telafi ve sosyal kaytarma teorileri kapsamında tartışması yapılmıştır.

Anahtar Kelimeler: Rol Belirsizliği, İş Tatmini, Isşten Ayrlma Niyeti, Sosyal Kaytarma.

\footnotetext{
* Bu çalışma, 18.Uluslararası İşletmecilik Kongresi, 02-04 Mayıs 2019, Osmaniye/ TÜRKIYE'de sunulmuştur.

** Dr.Öğr.Üyesi, Ankara Milli Savunma Üniversitesi KHO, mail:agursoy@kho.edu.tr, ORCID: 0000-0002-8408-2415

*** Dr.Öğr.Üyesi, Akdeniz Üniversitesi, mail:kemalkoksal@akdeniz.edu.tr, ORCID: 0000-0001-7653-1762

**** Öğr.Gör., Ankara Milli Savunma Üniversitesi KHO, mail:hyapar@kho.edu.tr,
} ORCID: 0000-0003-2362-7431

Geliş Tarihi/Received : 07.02.2019

Kabul Tarihi/Accepted : 23.05.2019

Araştırma Makalesi/Research Article DOI: 10.17134/khosbd.640547 


\title{
The Effect of Role Ambiguity on the Job Satisfaction and Intention to Leave
}

\begin{abstract}
It is stated that role ambiguity had negative impacts on employees' attitudes and behaviors by increasing job stress of employees. It was seen that studies which are about role ambiguity and job satisfaction have different results. Based on the different results of role ambiguity on job satisfaction, the aim of study is to test the impact of role ambiguity on job satisfaction by controlling the common method variance problem. For this purpose, data were collected in three weeks from 227 participants working in the public sector with one-week intervals by temporal separation. After common method analysis, regression and correlation analyses were performed to test hypotheses. Because of research conducted in a large-scale public institution, it was found that role ambiguity has a positive and significant effect on job satisfaction. The relationship of role ambiguity and intention to leave was also investigated to test this positive and significant effect. Role ambiguity has a significant and negative impact on intention to leave. The findings were argued, in the context of social loafing and social compensation theory.
\end{abstract}

Keywords: Role Ambiguity, Job Satisfaction, Intention to Leave, Social Loafing.

\section{Giriş}

Örgütler, bireylerin tek başlarına ulaşamayacakları amaçlara ulaşabilmek için bir araya gelen insanların oluşturduğu yapılardır. Örgütün yapısına bağlı olarak gerçekleştirilen iş bölümü ve uzmanlaşma sonucunda çalışanların rolleri ortaya çıkmıştır (Mintzberg, 1983). Farklı rol beklentilerine yönelik istekler çeliştiğinde, çalışanlar rol çatışması yaşayabilmektedir. Bu farklı rollere ilişkin çalışanın sahip olduğu bilgiler ile rolünün uygun bir şekilde yerine getirilmesi için gerekli olan bilgiler arasındaki uyuşmazlık da rol belirsizliğine neden olmaktadır. Rol çatışması ve rol belirsizliği rol stresini artırarak örgütsel sonuçlar üzerinde etkili olmaktadır (Kahn, Wolfe, Quinn, Snoek, ve Rosenthal, 1964). Rol çatışması ve rol belirsizliğinin öncülleri ve sonuçlarına ilişkin yapılan çalışmalar incelendiğinde, bu çalışmaların sonuçlarının çelişkili ve belirsiz olduğu görülmektedir (Fisher ve 
Gitelson, 1983; Jackson ve Schuler, 1985; Abramis, 1994). Jackson ve Schuler (1985) yaptıkları meta-analiz çalışmasında rol çatışması ve rol belirsizliğine yönelik yaklaşık 200 çalışmayı incelemişlerdir. $\mathrm{Bu}$ çalışmalarda verilerin çoğunluğunun kesitsel yöntem ve öz değerlendirme ölçeğiyle toplandığını, dolayısıyla ortak yöntem varyans (OYV) sorunu içerdiğini ve değişkenler arasındaki nedensel ilişkiyi tam olarak ortaya koyamadığını ifade etmişlerdir. Ayrıca rol belirsizliği ile iş tatmini arasındaki anlamlı fakat düşük korelasyonun OYV problemi nedeniyle sorgulanması gerektiğini belirtmişlerdir. Abramis (1994) yaptığı meta-analiz çalışmasında, bu çalışmada da veri toplama aracı olarak kullanılan, Rizzo vd. (1970) tarafından geliştirilen ölçek kullanılarak yapılan çalışmalarda, rol belirsizliği ile iş tatmini arasında anlamsız ilişkiyi gösteren çalışmaların yanında anlamlı bir ilişkiye ulaşan çalışmalarda da çok düşük açıklanan varyans oranı bulunduğunu raporlamıştır. Ayrıca rol belirsizliği ile işten ayrılma niyeti arasında da benzer durumun olduğu belirtilerek, rol belirsizliğinin işten ayrılma niyetini anlamlı bir şekilde artırdığı sonucuna ulaşan altı çalışma varken iki çalışmada da bu iki değişken arasında anlamlı bir ilişki bulunamamıştır. Ambrose vd. (2014) çok boyutlu rol belirsizliği ile iş tatmini arasındaki ilişkiyi inceledikleri çalışmada da müşteri, iş, terfi ve aileye yönelik belirsizlikle iş tatmini arasında doğrudan anlamlı bir ilişki tespit edemezken, üste yönelik belirsizliğin negatif bir etkisini tespit etmişlerdir.

Yukarıda bahsedilen meta-analiz çalışmalarında incelenen araştırmalar Batı ve Kuzey Amerika kıtasında yapılmıştır. Türk toplumunda yapılan çalışmaların sonuçları kültürel değerlerin etkisini içerdiğinden, rol teorisi yazını açısından önem taşımaktadır. Börk ve Adıgüzel (2015), rol belirsizliğinin genel iş tatmini üzerindeki etkisini inceledikleri çalışmada, rol belirsizliğinin iş tatmini üzerinde negatif ve anlamlı bir etkisi olduğunu $(\beta=-0,28, p<0,001)$ ve iş tatmindeki değişimin \%11'lik kısmının rol belirsizliği tarafından açıklandığını raporlamıştır. Kaplanoğlu (2014) çalışmasında rol belirsizliğinin tek başına iş tatmini üzerindeki değişimi açıklama gücünü \%8 (r=0,296) olarak bulmuştur. Ülbeği ve İplik (2017) tarafından yapılan çalışmada, yapısal eşitlik modeli ile rol belirsizliğinin iş tatmini üzerindeki doğrudan ve işe bağlılık aracılığıyla dolaylı etkisi incelenmiştir. Araştırma sonucunda, rol belirsizliğinin iş tatmini üzerinde negatif anlamlı toplam etkisinin (Effect=-0,279) olduğunu bulmuşlardır. Ceylan ve Ulutürk (2006) 151 kişiden toplanan verilerle Rizzo vd. (1970) tarafından geliştirilen ölçekle rol 
belirsizliği ve genel iş tatmini arasındaki ilişkiyi inceledikleri çalışmada, rol belirsizliğinin iş tatminini etkilemediği sonucuna ulaşmışlardır.

Sonuç olarak, rol belirsizliğinin iş tatmini üzerindeki farklı sonuçlarından hareketle, OYV problemi kontrol altına alınarak rol belirsizliği iş tatmini ve işten ayrılma niyeti ilişkisinin test edilmesi bu çalışmanın amacını oluşturmaktadır.

Çalışmada öncelikle değişkenler arasındaki ilişki kısaca açıklanarak, araştırma hipotezleri oluşturulmuştur. Daha sonra ise çalışmanın yöntemine ilişkin açıklamalar yapılarak araştırmada kullanılan analizlere değinilmiştir. Analiz bulguları raporlanarak, bulguların alan yazın kapsamında tartışması yapılacaktır.

\section{Kuramsal Çerçeve}

İş tatmini çalışanın işini değerlendirilmesinden kaynaklanan olumlu bir duygusal durum olarak tanımlanabilir (Waight ve Madera, 2011). Çalışanların işinden tatmin olması onun iş performansı ve örgütsel bağlılı̆g üzerinden olumlu etki yaratmaktadır. Çalışanlar arasındaki bireysel farklılıklar iş tatmini üzerinde etkili olsa da genel olarak işle ilgili birçok değişkenin iş tatmini ile doğrudan ve dolaylı etkisi olduğu yapılan çalışmalarla ortaya konulmuştur (Judge ve Klinger, 2007). Rol belirsizliğinin iş tatmini üzerinde etkisinin olduğu yapılan birçok araştırmanın konusu olmuştur. Yapılan çalışmalarda, rol belirsizliğinin rol stresini artırarak, iş tatminini olumsuz bir şekilde etkileyeceği kurgulanmış fakat elde edilen sonuçlar net olarak anlamlı bir olumsuz ilişkiyi göstermemektedir (Rizzo, House, ve Lirtzman, 1970; Fisher ve Gitelson, 1983; Ceylan ve Ulutürk, 2006; Börk ve Adıgüzel, 2015; Ülbeği ve İplik, 2017).

Rol teorisine göre, rol belirsizliği bireyin örgütteki görevini yerine getirmesi için ihtiyaç duyduğu bilgilerin eksikliği olarak tanımlanmaktadır (Kahn, Wolfe, Quinn, Snoek, ve Rosenthal, 1964). Çalışanın örgütteki rolüne ya da yapacağı işe yönelik olarak sorumluluğunun ne olduğu ve ondan ne beklendiğine ilişkin netliğin olmamasıdır (Ram, Khoso, Shah, Chandio, ve Shaikih, 2011). Çalışanın rolüne ilişkin belirsizliğin nedenleri olarak kişisel bilgi eksikliği (Khattak, Quarat-ul-ain, ve Iqbal, 2013), örgütsel yapının eksikleri, etik anlayış ve örgüt kültürü (Soltani, Hajatpour, Khorram, ve Nejati, 2013) sayılabilir. 
Çeşitli yazarlar tarafından rol belirsizliğinin farklı türleri olduğu ifade edilmiştir (Kahn, Wolfe, Quinn, Snoek, ve Rosenthal, 1964; Breaugh ve Colihan, 1994; Brun, Saetre, ve Gjelsvik, 2009). Rol belirsizliğinin alt türleri olarak beklentilere, davranışlara ve önceliklere yönelik belirsizlikler, konu ve kaynaklara yönelik belirsizlikler, yöntem, planlama ve performansa yönelik belirsizlikler sayılabilir. Rizzo vd. (1970), iş stresinin kaynağı olarak gösterdikleri rol belirsizliğini tek bir boyut olarak incelemişlerdir. İş stresinin diğer bir kaynağ 1 olarak da rol çatışmasını incelemişlerdir. Yazarlara göre rol belirsizliği ve rol çatışması, bireyin iş stresini artırarak olumsuz tutum ve davranışlara neden olmaktadır. Rol teorisi kapsamında yapılan çalışmaların çoğu incelendiğinde, rolüne ilişkin bilgi eksikliği ya da belirsizlik bireyde stres yaratmakta bu durum da başta iş performansı olmak üzere, iş tatmini, işten ayrılma niyeti ve örgütsel bağl1lı üzerinde olumsuz etkilerinin olduğu tespit edilmiştir (Ambrose, Rutherford, Shepherd, ve Tashchian, 2014; Amyx, Sharma, ve Alford, 2014).

Rol belirsizliği ve iş tatmini arasındaki ilişkiyi inceleyen bundan önceki çalışmaların çoğunda OYV probleminin göz ardı edildiği, dolayısıyla kesitsel yöntem kullanılarak yapılan bu çalışmaların sonuçlarının sorgulanması gerektiği belirtilmektedir (Jackson ve Schuler, 1985; Abramis, 1994). Bu araştırmada, bireyin algıladığı rol belirsizliği ile iş tatmini ve işten ayrılma niyeti arasındaki ilişki OYV probleminden arındırılmaya çalışılarak incelenmiştir. Yukarıda yapılan teorik açıklamalardan ve çalışmalardan yola çıkarak araştırmanın hipotezleri şu şekilde oluşturulmuştur.

H1: Rol belirsizliği iş tatminini anlamlı bir şekilde etkilemektedir.

H2: Rol belirsizliği işten ayrılma niyetini anlamlı bir şekilde etkilemektedir.

\section{Yöntem:}

Araştırma kesitsel bir araştırma olup araştırmada kullanılan değişkenlere ait verileri toplayabilmek için anket formu kullanılmıştır. Rol belirsizliği ve iş tatmini arasındaki ilişkiyi inceleyen önceki çalışmalarda yaşanan OYV probleminden kaçınmak amacıyla Podsakoff ve diğerleri (2003) tarafından önerilen ölçeklerin zamansal bölümlenmesi yöntemi ile anketler uygulanmıştır. $\mathrm{Bu}$ maksatla, anketlere özel bir kod verilerek ilk önce çalışanın yaşadığı rol belirsizliği algısı ölçülmüştür. Bir hafta aradan sonra aynı çalışanların (kodlara göre dağıtım 
yapılmıştır) iş tatmini ölçülmüş ve son olarak bir hafta sonra da işten ayrılma niyeti ölçülmüştür. OYV, sosyal bilimlerde ölçüm yöntemine bağlı olarak ortaya çıkabilecek potansiyel bir problemdir. OYV'ye neden olan faktörler olarak, bağımsız ve bağımlı değişkene ait verilerin aynı kaynaktan alınması ayrıca ölçek maddelerinden kaynaklanabilmektedir. Bağımsız ve bağımlı değişkene ait verilerin tek bir kaynaktan alınması durumunda öz değerlendirme sorunu ortaya çıkabilmektedir. Değerlendirici tutarlı cevaplar vermek adına gerçek durumu yansıtmayabilmektedir. Ayrıca bağımsız ile bağımlı değişken arasındaki gömülü teoriye uygun cevaplar vererek gerçekte var olmayan bir ilişki ortaya çıkarabilmektedir. Diğer bir engelde sosyal beğenilirlik nedeniyle gerçekte olmayan cevapların verilmesi sonucunda oluşabilmektedir (Podsakoff, MacKenzie, Lee ve Podsakoff, 2003).

Araştırmada kullanılan ölçeklere yönelik yapılan zamansal bölümlemeyle, OYV sorunu oluşmasını engellenmeye çalışılsa da OYV olup olmadığ istatistiksel olarak da kontrol edilmelidir. Bu maksatla, Harman'in tek faktör yöntemi kullanılmıştır. Yapılan hesaplama sonucunda anket formunda yer alan bütün değişkenler tek faktöre toplandığında açıklanan toplam varyans oranı $\% 42,8$ 'dir. Hesaplanan değer \%50'den küçük olduğundan ortak yöntem varyans sorunu bulunmamaktadır (Podsakoff, MacKenzie, Lee, ve Podsakoff, 2003).

\section{a. Araştırma Modeli:}

Teorik çerçeve kapsamında oluşturulan araştırma modeli aşağıda sunulmuştur.

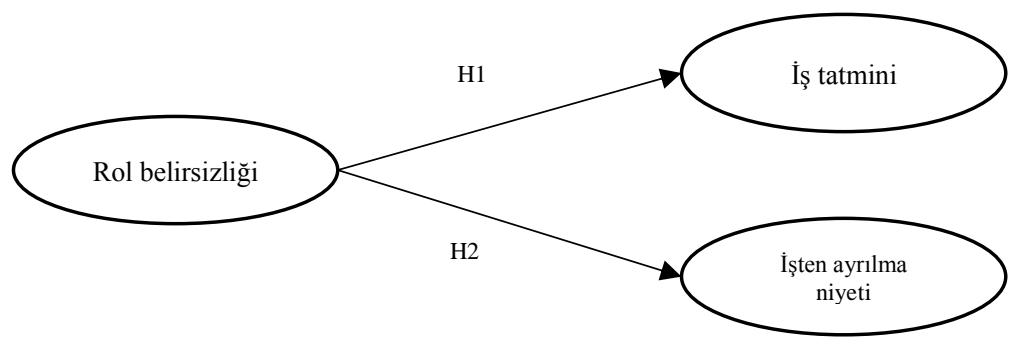

Şekil 1: Araştırmanın Kavramsal Modeli 


\section{b. Araştırmanın Örneklemi:}

Araştırmanın evrenini Ankara'da bulunan bir kamu kurumu oluşturmaktadır. Söz konusu kamu kurumunda çalışan sayısı 540 kişidir. \%95 güvenilirlik ile örneklem sayısının 225 olması gerektiği sonucuna ulaşılmıştır (Durmuş, Yurtkoru, ve Çinko, 2013). Örneklemi belirlerken kolayda örnekleme yöntemi kullanılmıştır. Doldurulmayacak ya da eksik ve hatalı doldurulabilecek veriler göz önüne alınarak 250 çalışana anket dağıtılmıştır. Anketlerden 235 tanesinden geri dönüş olmuştur. Geri dönüş oranı \%94'tür. Elde edilen veriler istatistik paket programına girildikten sonra uç ve kayıp değerleri belirleyebilmek için tarama işlemi yapılmıştır. $\mathrm{Bu}$ işlemin sonucunda çoğu soruya cevap verilmeyen ve uç değerlerin dışında bulunan 8 anket analizlere dâhil edilmemiş, 227 sağlıklı veri ile analizler yapılmıştır. Araştırma örneklemine ait demografik bilgiler: Katılımcıların cinsiyeti, yaşı, medeni ve eğitim durumu, toplam çalışma süresi ve mevcut kurumdaki çalışma süresi kapsamında değerlendirilmiştir. Çalışmaya katılanların \%3,4'ü 20-24, \%18,2'si 25-29, \%26,7'si 30-34, \%22,8'i 3539 ve \% 28,9'u 40 ve üzeri yaştadır. \%74'ü erkek, \%26's1 ise kadındır. Katılımcıların \%74'ü evli, \%26'sı bekârdır, \%23'ü lise, \%64'ü lisans ve \%13'ü ise lisansüstü mezunudur, \%68'i 5-10 y1llık toplam çalışma süresine sahiptir ve bulunduğu kurumda çalışma süresi 3-5 yıl olanların oranı \%76'dır.

\section{c. Araștırmada Kullanılan Ölçekler:}

Araştırmada kullanılan ve farklı zamanlarda toplanan anket dört bölümdür. İlk bölümde demografik bilgiler, ikinci bölümde rol belirsizliği algısını (ilk hafta uygulanan), üçüncü bölümde iş tatmini (ikinci hafta uygulanan) ve son bölümde ise işten ayrılma niyetini ölçen (son hafta uygulanan) ifadeler vardır. Ankette, demografik bilgileri tespit etmeye yönelik altı soru, rol belirsizliği algısını belirlemeye yönelik altı soru, iş tatmini ve işten ayrılma niyetini belirlemeye yönelik de üçer soru bulunmaktadır. Ölçeklerde verileri belirlemek için Beşli Likert yöntemi (1=Kesinlikle katılmıyorum, 5=Kesinlikle katılıyorum) ile veriler toplanmıştır.

Rol Belirsizliği Algısı Ölçeği: Rol belirsizliğini ölçmek için Rizzo ve arkadaşları (1970) tarafından geliştirilen ölçekten yararlanılmıştır. Altı sorudan oluşan ölçeğin güvenirlik katsayısı Cronbcah's Alpha 0,945'tir. 
İş Tatmini ve İşten Ayrılma Niyeti Ölçeği: Katılımcıların genel iş tatminlerini ve işten ayrılma niyetini ölçebilmek maksadıyla Camman vd. tarafindan (1983) geliştirilen üç soruluk ölçekler kullanılmıştır. Ölçeğin iç tutarl11ıkları sırasıyla 0,888 ve 0,886 (Cronbach's Alpha) olarak tespit edilmiştir. Her üç ölçek de daha önce Türkçe yapılan birçok çalışmada geçerliliği ve güvenilirliği test edilmiş ölçeklerdir. Bu çalışmada da ölçeğin güvenilirlik katsayıları incelendiğinde ölçeklerin oldukça güvenilir oldukları görülmektedir.

Araştırmada kullanılan üç ölçeğin geçerliliğini kontrol etmek için doğrulayıcı faktör analizi (DFA) yapılmıştır (Tablo 1). Tablo 1'deki değerler modellerin modifikasyonundan sonra bulunan değerlerdir. Tablo incelendiğinde ölçeklerin hepsinin iyi uyum değerlerine sahip oldukları görülmekte ve ölçeklerin tek faktörlü yapıları doğrulanmaktadır (Hair, Black, Babin, ve Anderson, 2010). Çalışmada yapı geçerliliğini kontrol etmek amacıyla bileşim ve ayrışım geçerliliği de kontrol edilmiştir. Rol belirsizliği ölçeğinde (faktör yükleri: 0,882, 0,899, 0,848, $0,893,0,927,0,819)$ ortalama açılanan ortalama varyans 0,77 , bileşik güvenilirlik 0,95'tir. İş tatmini ölçeğinde (faktör yükleri: $0,893,0,909,0,755$ ) açıklanan ortalama varyans 0,73 , bileşik güvenilirlik 0,89 'dur. İşten ayrılma niyeti ölçeğinde (faktör yükleri: $0,853,0,898,0,806$ ) ise 0,72 , bileşik güvenilirlik $0,88^{\prime}$ dir. Sonuçlar incelendiğinde ölçeklerin yapı geçerliliği değerlerinin iyi seviyede olduğu görülmektedir. Ayrışım geçerliliği için ise değişkenler arasındaki paylaşılan toplam varyans ile açıklanan ortalama varyans rakamları karşılaştırılmıştır. Sonuca göre paylaşılan toplam varyansın, açıklanan ortalama varyanstan düşük olduğu (açıklanan ortalama varyans: $0,77,0,73,0,72$; paylaşılan toplam varyans: 0,29, $0,20,0,20$, değerler rol belirsizliği, iş tatmini ve işten ayrılma niyeti şeklindedir) için değişkenler arasında ayrışım geçerliliği olduğu da görülmektedir. Tüm bu sonuçlara göre ölçeklerin yapı geçerliliği doğrulandığından sonraki analizlere geçilmiştir. 
Tablo 1: Doğrulayıcı Faktör Analizi Sonuçları

\begin{tabular}{lllllllll}
\hline Ölçek & $\chi^{2}$ & sd & $\chi^{2 / s d}$ & RMSEA & CFI & GFI & NFI & RMR \\
\hline $\begin{array}{l}\text { Rol Belirsizliği } \\
\text { Alg1s1 }\end{array}$ & $13,943^{*}$ & 8 & 1,743 & 0,057 & 0,996 & 0,980 & 0,990 & 0,013 \\
İş Tatmini & $0,264^{*}$ & 1 & 0,264 & 0,000 & 1,000 & 0,999 & 0,999 & 0,013 \\
İşten Ayrilma Niyeti & $3,701^{*}$ & 1 & 3,701 & 0,109 & 0,993 & 0,989 & 0,990 & 0,068 \\
\hline
\end{tabular}

$* \mathrm{p}>0,05$

\section{ç. Analiz ve Bulgular}

Verileri analiz edebilmek için SPSS ve AMOS paket programları kullanılmıştır. Bağımsız değişken olan rol belirsizliğinin bağımlı değişkenler üzerindeki etkisini tespit etmek maksadıyla yapılan çalışmada ölçeklerin tek faktörlü yapı geçerliliğini belirlemede AMOS programından yararlanılmıştır. Değişkenler arasındaki ilişkilerin hem derecesi hem de yönünü belirlemek için korelasyon analizi ve sonrasında da regresyon analizi yapılmıştır.

Rol belirsizliği algısı, iş tatmini ve işten ayrılma niyeti değişkenlerine ait ortalama, standart sapma ve korelasyon analizinin sonuçları Tablo 2'de gösterilmiştir.

Tablo 2: Ortalama, Standart ata ve Pearson Korelasyonu

\begin{tabular}{lccccc}
\multicolumn{1}{c}{ Değişkenler } & Ort. & S.S. & (RBZA) & (IT) & (İAN) \\
\hline Rol Belirsizliği Algısı (RBZA) & 3,623 & 0,928 & 1 & & \\
İş Tatmini (İT) & 3,298 & 1,004 & $0,502^{*}$ & 1 & \\
İşten Ayrılma Niyeti (İAN) & 2,334 & 1,097 & $-0,413^{*}$ & $-, 0,422^{*}$ & 1 \\
\hline$* \mathrm{p}<0,01$ & & & & &
\end{tabular}

Rol belirsizliği algısının ortalaması 3,623 (s.s. $=0,928$ ), iş tatmininin ortalamas1 3,298 (s.s.=1,004) ve işten ayrılma niyetinin ortalamas1 2,334 $($ s.s. $=1,097)$ olarak hesaplanmıştır. Sonuçlar incelendiğinde rol belirsizliği algısı ve 
iş tatmininin ortalamasının yüksek olduğu, işten ayrılma niyeti ortalamasının ise diğer iki değişkene göre düşük olduğu görülmektedir.

Korelasyon analiz sonuçları değerlendirildiğinde ise rol belirsizliği algısı ile iş tatmini arasında pozitif, orta düzeyde ilişki olduğu $(r=0,502, p<0,01)$ ayrıca rol belirsizliği algısıyla işten ayrılma niyeti arasında negatif, orta düzeyde $(\mathrm{r}=$ 0,413, p<0,01) ilişki olduğu görülmektedir. Rol belirsizliği algısıyla tatmini arasındaki pozitif ilişkinin ortaya çıkması iki değişkenin birlikte değiştiğini, rol belirsizliği algısıyla ayrılma niyeti arasında tespit edilen negatif ilişki ise iki değişkenin ters yönlü azalıp ya da arttığını göstermektedir.

Rol belirsizliği algısının, tatmin ve ayrılma niyeti arasındaki ilişkiyi regresyon denklemi ile açıklamak, gözlenen değişimin ne kadarını açıkladığını belirlemek ve rol belirsizliği algısının bağımlı değişkenler üzerindeki etkilerinin anlamlı olup olmadığını ve önem derecesini belirlemek amacıyla basit regresyon analizi yapılmıştır. Analiz sonucundaki değerler Tablo 3 'tedir. Basit regresyon analiz sonuçları istatistiksel olarak anlamlıdır. Sonuçlara göre rol belirsizliği algısı iş tatmini yordamaktadır $\left(\beta=0,502, p<0,00, F=75,661 \mathrm{R}^{2}=0,252\right)$. Bu değer iş tatminindeki \%25,2'lik varyansın rol belirsizliği algısına bağlı olduğunu ifade etmektedir. Ayrıca rol belirsizliği algısı işten ayrılma niyetini yordamaktadır ( $\beta=$ $\left.0,413, \mathrm{p}<0,00, \mathrm{~F}=46,146 \mathrm{R}^{2}=0,170\right)$. İşten ayrılma niyetindeki \%17'lik varyans, rol belirsizliği algısına bağlı olduğu görülmektedir. Bu sonuçlara göre araştırmanın bir ve iki numaralı hipotezleri desteklenmiştir.

Tablo 3: Basit Regresyon Analizi Sonuçları $(n=227)$

\begin{tabular}{llcccc}
\hline Bağımsız Değişken & Bağımlı Değişken & $\boldsymbol{\beta}$ & $\mathbf{R}^{\mathbf{2}}$ & $\mathbf{t}$ & $\mathbf{p}$ \\
\hline \multirow{2}{*}{ Rol Belirsizliği Algısı } & İş Tatmini & 0,543 & 0,252 & 8,698 & 0,000 \\
& İşten Ayrılma Niyeti & $-0,488$ & 0,170 & $-6,793$ & 0,000 \\
\hline
\end{tabular}

Tartışma ve Sonuç

Rol teorisine göre, rol çatışması ve rol belirsizliği çalışanların iş stresini artırarak örgütsel sonuçlar üzerinde olumsuz bir şekilde etkili olmaktadır. Rol belirsizliği ile iş tatmini arasındaki ilişkiyi inceleyen ilk çalışmalarda, rol 
belirsizliğinin iş stresini artırarak iş tatminini olumsuz bir şekilde etkilediği ifade edilmiştir (Boles vd., 1997). Jackson ve Schuler (1985)'in rol teorisiyle ilgili 200'e yakın araştırmayı inceledikleri çalışmada, bu araştırmaların \%85'inde Rizzo vd. (1970) tarafından geliştirilen ölçeğin kullanıldığını, ölçeğin rol çatışması ve rol belirsizliğini ölçmede oldukça geçerli ve güvenilir olduğunu ifade etmişlerdir. Ancak Fisher ve Gitelson (1983), ölçeklerin geçerliliğinin yüksek olsa da bu konuda yapılan araştırmaların rol çatışması ve rol belirsizliğinin öncülleri ve sonuçları hakkında tartışmalı ve belirsiz sonuçları olduğunu ifade etmiştir. Ambrose ve diğerleri (2014) yaptıkları çalışmada, rol belirsizliğinin iş tatminini anlamlı bir şekilde etkilemediğini tespit etmişlerdir. Batı kültürüne ait bu çalışmaların yanında Türk kültüründe de rol teorisinin testine yönelik yapılan çalışmalarda da tartışmalı ve belirsiz sonuçlar ortaya çıkmıştır (Ceylan ve Ulutürk, 2006; Ülbeği ve İplik, 2017). Yaptığımız araştırmada özellikle OYV problemi (sosyal beğenilirlik) olmadan, çok sayıda çalışanı olan bir kurumda rol belirsizliğinin iş tatmini üzerindeki etkisi incelenmeye çalışılmıştır. Araştırma bulgularını test etmek amacıyla da işten ayrılma niyeti ikinci bağımlı değişken olarak modele dâhil edilmiştir. Araştırmanın sonucu, Ambrose (2014) ve Ceylan ve Ulutürk (2006) tarafindan yapılan çalışmalardaki rol belirsizliği ile iş tatmini arasındaki negatif ilişki çıkmamasını destekler niteliktedir. Fakat çalışmamızda diğer çalışmalardan farklı olarak, rol belirsizliğinin iş tatminini anlamlı ve pozitif bir şekilde yordadığ 1 tespit edilmiştir.

Yukarıda açıklanan rol belirsizliğinin iş tatmini üzerindeki etkisini inceleyen çalışmalarda farklı sonuçların çıkmasının temel nedeni, rol belirsizliğinin sosyal telafi ve sosyal kaytarma teorileri çerçevesinde iki boyutlu etkisi ile açıklanabilir. Rol teorisi, rol çatışmasının ve rol belirsizliğinin iş stresini artırarak örgütsel sonuçlar üzerinde olumsuz etkileri olacağını ileri sürmektedir. Bu etki sosyal telafi teorisi kapsamında açıklanabilir. Çok sayıda çalışanı bulunan kamu kurumunda ya da özel kurumda, görevlerin, özellikle sosyal telafi teorisi çerçevesinde, diğerlerinin göstermediği performans için fazladan çaba gösteren (Williams ve Karau, 1991), işi takip eden ve iç kontrol odağ1 yüksek çalışanlara (Akbolat vd., 2011) verildiğinden bu çalışanların rol stresi artmaktadır. Sosyal telafi teorisi kapsamında diğerlerinin göstermediği çaba için fazladan çaba gösteren çalışanın rol belirsizliğinden iş tatmini olumsuz etkilenebilmektedir. Rol belirsizliği ile iş tatmini ve işten ayrılma niyeti arasındaki olumlu ilişki, ikinci 
boyut olan sosyal kaytarma teorisi kapsamında açıklanabilir. Sosyal kaytarma, çalışanların grup içindeyken, tek başlarına ortaya koydukları performansı göstermemeleri olarak tanımlanabilir (George, 1992). Günümüz organizasyonlarında takım çalışması, sinerji etkisiyle popüler olmuş ve birçok örgütte uygulanmaya başlamıştır. Ancak takım çalışmasında işlerin karşılıklı bağımlılık özelliği göstermesi sosyal kaytarmayı artırmaktadır. Ayrıca çalışanların yaptığ 1 islerin görünürlü̆̈̈̈ ve ölçülebilirliğinin az olması da sosyal kaytarmayı artıran nedenler olarak gösterilmektedir (Simms ve Nichols, 2014). Çalışanların rol belirsizliği yaşamasının nedenleri arasında, örgütlerin büyüyerek karmaşık bir yapıya sahip olması, örgütün yapılanmada değişikliğe gitmesi ve yöneticilerin çalışanlara açık görevler verememesi ya da bilgi akışını yeterince sağlayamaması sayılmaktadır. Örgütsel büyümeye bağlı olarak yöneticilerin kontrol alanı, maliyetleri azaltmak, hızlı karar almak ve esnekliği artırmak gibi nedenlerle genişletilmiştir. Artan kontrol alanı yöneticinin, çalışanların görevlerini takip etmesinde ve her birine açık emirler vermesinde sıkıntılar yaratmaktadır (Robbins ve Judge, 2012). Bunun yanında takım çalışmasının sağladığı sinerjiden faydalanmak adına takım çalışmalarına olan ilgi de artmıştır. Büyüyen örgüt yapısı, genişleyen kontrol alanı ve artan takım çalışmaları sonucunda görev görünürlüğü azalmıştır. Görev görünürlügünün azalması da çalışanları sosyal kaytarmaya yönlendirmektedir (Latané vd., 1979). Çalışanın tek başına ortaya koyduğu performans tespit edilerek bu performansın diğer çalışanlarınkiyle karşılaştırılabildiği durumlarda sosyal kaytarma azalmaktadır (Harkins ve Petty, 1982). Görev görünürlüğünün azalması çalışanlardaki değerlendirilme kaygısını da azaltmaktadır. Değerlendirilme kaygısı azalan çalışan tek başına ortaya koyduğu çabayı, grup içinde kendi rolü belirsiz olduğunda azaltabilmektedir. Grup içinde kaybolan, rolü belirsiz bir çalışan diğerlerine göre daha az çaba göstererek mevcut kazançlarını koruyabileceğinden, bu durum çalışanda olumsuz tutum ve davranışlara neden olmayabilmektedir. Rol belirsizliği nedeniyle sosyal kaytarma yapan çalışanlar (Harkins ve Szymanski, 1989) daha az çaba ile yine mevcut çıktıları elde etmeye devam edeceğinden iş tatminin de azalma olmazken artış bile olabilecektir.

Rol belirsizliği konusunda son dönemde yapılan çalışma sonuçları araştırma bulgularını kısmen destekler niteliktedir. Judeh (2011), örgütte görev ve sorumlulukların net bir şekilde belirlenmediği zaman çalışanların sorumluluk almaktan kaçındığını ifade etmektedir. Sorumluluğu az olan kamu çalışanının 
(memurluk anlayışı çerçevesinde) iş tatmininde azalma olmaması ya da işten ayrılma niyetinde artış olmaması beklenebilir. Johlke ve Iyer (2013) satış elamanlarının müşteri, etik ve yöneticilere yönelik rol belirsizliğinin iş tatmini üzerindeki etkisini inceledikleri çalışmalarında, müşteri ve etik belirsizliğin iş tatmini üzerinde anlamlı bir etkisi olmadığını, yönetici belirsizliğinin ise iş tatminini anlamlı ve olumsuz olarak etkilediğini tespit etmişlerdir. Amyx ve diğerleri (2014) de rol belirsizliğinin iş performansı üzerinde doğrudan ve anlamlı bir etkisi olmadığını ifade etmişlerdir. Bluhm (2009) tarafından yapılan araştırmanın bulgularını destekler niteliktedir. Bluhm çalışmasında, takım ya da grup çalışmalarında görevin tamamlanamaması durumda bile grup üyelerinin sonuçtan tatmin olabileceğini ileri sürmektedir. Çünkü bireyler tek başına olduklarında daha fazla çaba göstermek zorunluluğu yaşarken grup içinde daha az çaba gösterebilmekte ve başarısızlığın sonucu grup üyeleri arasında paylaştırılmaktadır. $\mathrm{Bu}$ sonuçlar rol teorisi kapsamında oluşturulan rol belirsizliğinin örgütsel sonuçlar üzerindeki etkilerinin farklı olabildiğini göstermektedir. Sosyal kaytarma teorisi çerçevesinde açıklamaya çalıştı̆̆ımız bu sonucun OYV problemi olmadan yapılacak diğer çalışmalarla desteklenmesi gerekmektedir.

Araştırma bulgularının yönetici ve araştırmacılar açısından çeşitli katkıları mevcuttur. Araştırmanın bulguları, rol belirsizliği konusunda yapılan diğer araştırmaların bulgularıyla birlikte değerlendirildiğinde, özellikle büyük örgütlerde ve takım çalışmasının yaygın olduğu organizasyonlarda çalışanlar rol belirsizliği yaşadığında, sosyal kaytarma kapsamında daha az çaba sarf ederek mevcut çıktılarını koruduklarından iş tatminleri artmakta ve de işten ayrılma niyeti gibi diğer örgütsel değişkenler üzerinde olumsuzluk yaşamayabilmektedir. Ancak rolü belirsiz olduğu için kaytaran çalışanın göstermediği çabayı, sosyal telafi teorisi kapsamında göstermek zorunda kalan çalışanın rol belirsizliği onun iş tatminini azaltabilmektedir. $\mathrm{Bu}$ yüzden yöneticiler görev görünürlüğü ve performans değerlendirmesini iyi yaparak sosyal kaytarmaya imkân vermemelidir. İlgili yazın açısından değerlendirildiğinde, araştırmanın, sosyal kaytarma çerçevesinde rol belirsizliğinin iş tatminini anlamlı ve olumlu bir şekilde etkileyeceğini göstermesi açısından önemli olduğu düşünülmektedir. Ayrıca sosyal beğenilirlik kısıtı yüzünden ölçülemeyen sosyal kaytarma davranış1 yerine, görev görünürlüğü ölçülerek rol belirsizliğinin iş tatmini üzerindeki etkisinde görev görünürlüğünün ve/veya ölçülebilirliğinin düzenleyici rolü incelenebilir. Böylelikle görev 
görünürlügü düşük olan çalışan ile görev görünürlüğü yüksek olan çalışanın iş tatmininin nasıl etkilendiği incelenebilir. Kolayda örnekleme yöntemiyle veri toplandığından araştırma bulgularının genellemesi yapılamamaktadır.

\section{Extended Summary}

\section{Introduction}

Role conflict and role ambiguity have an impact on organizational outcomes by increasing role stress (Kahn, Wolfe, Quinn, Snoek, ve Rosenthal, 1964). The results of these studies are contradictory and ambiguous (Fisher ve Gitelson, 1983; Jackson ve Schuler, 1985; Abramis, 1994). Jackson and Schuler (1985) examined about 200 studies on role conflict and role ambiguity in their meta-analysis. In these studies, the majority of the datas were collected by the cross-sectional method and self-assessment scale, and therefore, the common method variance (CMV) problem did not fully reveal the causal relationship between the variables.

The reasons why employees experience role ambiguity include the fact that the organizations have a complex structure, they change the structure of the organization, and the managers cannot provide the employees with clear tasks or they cannot provide enough information (Kahn, Wolfe, Quinn, Snoek, ve Rosenthal, 1964). As a result of the growing organizational structure, expanding control area and increasing team work, the visibility of the task has decreased. Reducing the visibility of the task also leads the employees to social loafing (Latané, Williams, ve Harkins, 1979). When the performance of the employee alone is determined and the performance can be compared with that of other employees, social loafing can be reduced (Harkins ve Petty, 1982).

The main reason for the different results in the studies investigating the impact of the role ambiguity on job satisfaction, is that the role ambiguity experienced as a result of tasks that cannot be given or cannot be followed in the complex organization causes positive work attitudes in the context of social loafing. Previous studies in the West, especially in Turkey, used the cross-sectional method and CMV problem is ignored. It is seen that $10-15 \%$ variance can be explained by even in theoretically unrelated variables. Therefore, CMV problem in 
cross-sectional studies is a very important constraint affecting the validity of research findings (Podsakoff, MacKenzie, Lee, ve Podsakoff, 2003).

In conclusion, based on the different results of role ambiguity on job satisfaction, it is the aim of this study to re-test the relationship between role ambiguity and job satisfaction by controlling the CMV problem in the context of social loafing.

Based on the above-mentioned theoretical explanations and studies, the hypotheses of the research were formed as follows.

Hypothesis 1: Role ambiguity affects job satisfaction significantly.

Hypothesis 2: Role ambiguity affects the intention to quit the job significantly.

\section{Method}

The research's method was a cross-sectional study and the convenience sample method was used to collect data. In order to avoid the CMV problem in previous studies examining the relationship between role ambiguity and job satisfaction, questionnaires were applied by temporal segmentation of the scales proposed by Podsakoff et al. (2003). For this purpose, a special code was given to the questionnaires and the perception of role ambiguity experienced by the employee was measured first. After one week, job satisfaction of the same employees (distribution according to codes) was measured and finally the intention to leave the job was measured one week later.

Even if CMV is tried to be prevented by the temporal segmentation of the scales, CMV should be checked statistically. For this purpose, Harman's single factor method was used. As a result, the total variance ratio explained in the survey form is $42,8 \%$. Since the calculated value is less than $50 \%$, there is no CMV problem (Podsakoff, MacKenzie, Lee, ve Podsakoff, 2003).

\section{Analysis and Findings}

The mean of role ambiguity was 3,623 (s.s.=0,928); the mean of job satisfaction was 3,298 (s.s. $=1,004)$ and the mean of job intention was calculated as 2,334 (s.s. $=1,097$ ). When the results are examined, it is seen that the mean of 
perception of role ambiguity and job satisfaction is high than the average value (3) and, the mean of intention to leave is lower than the other two variables.

When the correlation analysis results were evaluated, there was a positive relationship between role ambiguity and job satisfaction $(r=0.502, p<0.01)$ It is seen that there is a relationship. The existence of a positive relationship between the perception of role ambiguity and satisfaction shows that the two variables change together.

To explain the relationship between role ambiguity perception (independent variable), job satisfaction (dependent variable) and intention to leave (dependent variable) by regression equation, to determine how much change observed, and to determine whether the effects of role ambiguity on dependent variables are significant and to test the working hypotheses, simple regression analysis was performed. The results of the analysis are in Table 3. The results of simple regression analysis were statistically significant. According to the results, perception of role ambiguity predicted job satisfaction $(\beta=0.502, \mathrm{p}<0.00, \mathrm{~F}=$ $75,661 \mathrm{R} 2=0,252)$. This value indicates that the $25.2 \%$ variance in job satisfaction depends on the perception of role ambiguity. In addition, the role ambiguity perception predicts the intention to quit $(\beta=-0,413, \mathrm{p}<0,00, \mathrm{~F}=46,146 \mathrm{R} 2=$ $0,170)$. According to these results, one and two hypotheses of the study were supported.

\section{Discussion and Conclusion}

In our study, the effect of role ambiguity on job satisfaction in a public organization, which has a large number of employees, was examined, especially without the problem of CMV. In order to test the findings of the research, the intention to quit was included as second dependent variable in the model. The results of the study explain why there is no negative relationship between job ambiguity and role ambiguity in studies conducted by Ambrose et al., (2014) and Ceylan and Ulutürk (2006). Unlike other studies in our study, role ambiguity predicted job satisfaction significantly and positively. The results of the study support the findings of the study by Bluhm (2009). In the Bluhm study, even if the task is not completed in team or group work, it suggests that group members may be satisfied with the result. Because individuals have to make more efforts when 
they are on their own, they can make less effort within the group and the result of failure is shared among group members. The research findings that we have tried to explain within the framework of social loafing theory should be supported by other studies.

Role theory suggests that role conflict and role ambiguity will have negative effects on organizational outcomes by increasing job stress. In our opinion, especially the role ambiguity has two-dimensional effect within the framework of social compensation and social loafing theories. The first dimension can be explained within the scope of social compensation theory. A large number of employees in public or private institutions, especially within the framework of social compensation theory, others who do not show extra effort for performance (Williams ve Karau, 1991), who follow the work and who have high levels of internal control (Akbolat, Işık, ve Uğurluoğlu, 2011), the role stress of these employees is increasing. Within the scope of social compensation theory, job satisfaction can be negatively affected by the role ambiguity of the employee who makes extra efforts for the effort not shown by others. The second dimension can be explained in the context of social loafing theory. As the employee, whose role is unclear as previously explained, can achieve the current outputs with less effort by moving towards social loafing, job satisfaction can be positively influenced by role ambiguity.

\section{Kaynakça}

\section{Makaleler}

Abramis, D. J. (1994). Work role ambiguity, job satisfaction, and job performance: meta-analyses and review. Psychological Reports, 75, 1411-1433.

Akbolat, M., Işık, O., ve Uğurluoğlu, Ö. (2011). Sağlık çalışanlarının kontrol odağı, iş doyumu, rol belirsizliği ve rol çatışmasının karşılaştırılması. H.Ü. İktisadi ve İdari Bilimler Fakültesi Dergisi, 29(2), 23-48.

Ambrose, S. C., Rutherford, B. N., Shepherd, C. D., ve Tashchian, A. (2014). Boundary spanner multi-faceted role ambiguity and burnout:An exploratory study. Industrial Marketing Management, 43, 1070-1078. 
Boles, J. S., Johnston, M. W., ve Hair, J. F. (1997). Role stress, work-family conflict and emotional exhaustion: Inter-relationships and effects on some work-related consequences. Journal of Personal Selling and Sales Management, 17(1), 17-28.

Börk, A., ve Adıgüzel, O. (2015). Rol çatışması ve rol belirsizliğinin iş tatmini ve örgütsel bağlılık üzerine etkisi: Kıyı Ege Bölgesi'ndeki bankacılık sektörü üzerine bir çalışma. International Periodical for the Languages, Literature and History of Turkish or Turkic, 10(10), 249-266.

Ceylan, A., ve Ulutürk, Y. H. (2006). Rol belirsizliği, rol çatışması, iş tatmini ve performans arasındaki ilişkiler. Doğuş Üniversitesi Dergisi, 7(1), 48-58.

Fisher, C. D., ve Gitelson, R. (1983). A meta-analysis of the correlates of role conflict and ambiguity. Journal of Applied Psychology, 68, 320-333.

George, J. M. (1992). Extrinsic and intrinsic origins of perceived social loafing in organizations. Academy of Management Journal, 35, 191-202.

Harkins, S. G., ve Petty, R. E. (1982). Effects of task difficulty and task uniqueness on social loafing. Journal of Personality and Social Psychology, 43(6), 1214-1229.

Harkins, S. G., ve Szymanski, K. (1989). Social Loafing and Group Evaluation. Journal of Personality and Social Psychology, 56(6), 934-941.

Jackson, S. E., ve Schuler, R. S. (1985). A Meta-analysis and Conceptual Critique of Research on Role Ambiguity and Role Conflict in Work Settings. Organizational Behavior and Human Decision Processes, 36(1), 16-55.

Kaplanoğlu, E. (2014). Mesleki stresin temel nedenleri ve muhtemel sonuçları: Manisa ilindeki SMMM'ler üzerine bir araştırma. Muhasebe ve Finansman Dergisi, 131-150.

Latané, B., Williams, K., ve Harkins, S. (1979). Many hands make light the work: The causes and consequences of social loafing. Journal of Personality and Social Psychology, 37, 822-832.

Podsakoff, P. M., MacKenzie, S. B., Lee, J. Y., ve Podsakoff, N. P. (2003). Common Method Biases in Behavioral Research: A Critical Review of the Literature and Recommended Remedies. Journal of Applied Psychology, 88(5), 879-903.

Simms, A., ve Nichols, T. (2014). Social loafing: A review of the literature. Journal of Management Policy and Practice, 15(1), 58-67. 
Waight, J., ve Madera, J. M. (2011). Diversity training: examining minority employees' organizational attitudes. Worldwide Hospitality and Tourism Themes, 3(4), 365-376.

Williams, K. D., ve Karau, S. J. (1991). Social loafing and social compensation: The effects of expectations of co-worker performance. Journal of Personality and Social Psychology, 61(4), 570-581.

\section{Bildiriler}

Ülbeği, İ. D., ve İplik, E. (2017). Rol belirsizliği, rol çatışması ve aşırı rol yükünün iş tatmini üzerine etkisinde işe bağl1lığın rolü. Uluslararası Yönetim İktisat Ve İşletme Kongresi Bildiriler Kitabı (s. 339-349). Zonguldak: Bülent Ecevit Üniversitesi.

\section{Kitaplar}

Durmuş, B., Yurtkoru, E., ve Çinko, M. (2013). Sosyal Bilimlerde SPSS'le Veri Analizi. İstanbul: Beta.

Hair, J. F., Black, W. C., Babin, B. J., ve Anderson, R. E. (2010). Multivariate Data Analysis: A Global Perspective (7 b.). New Jersey: Pearson Prentice Hall.

Judge, T. A., ve Klinger, R. (2007). Job satisfaction: Subjective well-being at work. M. Eid, ve R. Larsen içinde, The science of subjective well-being (s. 393413). New York: NY: Guilford Publications.

Mintzberg, H. (1983). Structure in Fives: Designing Effective Organizations. NJ: Prentice Hall.

Robbins, S. P., ve Judge, T. A. (2012). Örgütsel Davranış (14 b.). (E. İ. Erdem, Çev.) Ankara : Nobel Yayın.

\section{Diğer}

Bluhm, D. J. (2009). Adaptive consequences of social loafing. Academy of Management Annual Meeting Proceedings, 1-6. 
Kahn, R. L., Wolfe, D. M., Quinn, R. P., Snoek, J. D., ve Rosenthal, R. A. (1964). Organizational stress: Studies in role conflict and ambiguity. New York: Wiley.

Rizzo, J. R., House, R. .., ve Lirtzman, S. I. (1970). Role conflict and ambiguity in complex organizations. Administrative Science Quarterly, 15, 150-163. 